\section{A ÉTICA DO APRIMORAMENTO COGNITIVO: EFEITO FLYNN E A FALÁCIA DOS TALENTOS NATURAIS}

\section{THE ETHICS OF COGNITIVE ENHANCEMENT: FLYNN EFFECT AND THE NATURAL TALENTS FALLACY}

\author{
MARCELO DE ARAUJO' \\ (UERJ-CNPq / UFRJ - Brasil)
}

\begin{abstract}
RESUMO
O debate contemporâneo sobre a ética do aprimoramento cognitivo tem se concentrado sobretudo na pergunta sobre se, e em que medida, os indivíduos deveriam ou não ter o direito a fazer uso de novas tecnologias na expectativa de aumentar suas respectivas faculdades cognitivas. A pergunta sobre se haveria uma obrigação de implementarmos o aprimoramento cognitivo dos indivíduos não tem recebido muita atenção. Neste artigo, eu defendo a tese segundo a qual o Estado tem, em princípio, a obrigação de promover o aprimoramento cognitivo dos seus cidadãos. $\mathrm{O}$ argumento envolve uma análise do denominado efeito Flynn e das políticas públicas para a educação de crianças superdotadas. A obrigação que o Estado tem de promover o aprimoramento cognitivo de seus cidadãos está subordinada ao conhecimento disponível sobre a eficácia e a segurança dos procedimentos para fins de aprimoramento cognitivo.
\end{abstract}

Palavras-chave: aprimoramento cognitivo; talentos; efeito Flynn; superdotação

\begin{abstract}
The contemporary debate on the ethics of cognitive enhancement has mainly focused on the question whether, and to which extent, individuals should be granted the right to make use of new technologies in order to enhance their own cognitive powers. The question on the existence of a duty to implement the cognitive enhancement of the individuals has received less attention. In this paper, I argue that the state has a prima facie duty to pursue the cognitive enhancement of its citizens. The argument involves an analysis of the so-called effect Flynn and of the public policies for the education of gifted children. The duty the state has to further the cognitive enhancement of its citizens is qualified by our knowledge of the efficacy and the safety of the procedures used for cognitive enhancement.
\end{abstract}

Keywords: cognitive enhancement; talents; Flynn effect; gifted children

\section{Introdução}

Argumentos em favor do "aprimoramento cognitivo" geralmente envolvem o apelo à "liberdade" do indivíduo ${ }^{2}$. A ideia básica aqui é que, contanto que a integridade física ou mental de outras pessoas não seja colocada em risco, cada indivíduo deveria ter o direito de decidir por si próprio se é ou não de seu interesse fazer uso de tecnologias que têm o potencial para ampliar os limites de suas capacidades cognitivas. Outras pessoas, e o Estado especialmente, não deveriam impedi-lo de pelo menos tentar implementar esse interesse. Mas esse tipo de defesa do aprimoramento cognitivo geralmente não envolve a 
suposição de que o indivíduo tenha qualquer obrigação de aprimorar suas capacidades cognitivas, ou que o Estado tenha a obrigação de promover o aprimoramento cognitivo de seus cidadãos. $\mathrm{O}$ argumento relativo à liberdade do indivíduo me parece, em linhas gerais, válido e não pretendo discutir aqui esse ponto. ${ }^{3} \mathrm{O}$ que me interessa neste artigo é discutir a questão da obrigação. A tese que defendo neste artigo é que o aprimoramento cognitivo dos cidadãos deve ser promovido pelo Estado como uma questão de saúde pública. As razões para a promoção coletiva do aprimoramento cognitivo são basicamente as mesmas razões que podem ser alegadas em favor de outros tipos de políticas públicas tais como, por exemplo, a vacinação em massa da população, a iodização do sal, ou a criação de programas de educação especial para crianças superdotadas.

\section{Dois cenários hipotéticos}

Como ponto de partida para a discussão sobre a questão do aprimoramento cognitivo, eu gostaria de introduzir dois cenários hipotéticos. A discussão sobre esses dois cenários hipotéticos me permitirá, por um lado, esclarecer o que compreendo por "aprimoramento cognitivo"; por outro lado, essa discussão me permitirá também lidar com uma objeção recorrente no debate sobre o aprimoramento cognitivo, a saber: a objeção que alega que a busca pelo aprimoramento cognitivo - seja ao nível individual ou coletivo - é moralmente errada porque essa é uma prática pouco "natural”. Para essa objeção, a busca pelo aprimoramento cognitivo representa uma ameaça à natureza humana. ${ }^{4}$

Vejamos os dois cenários hipotéticos. No primeiro cenário hipotético, médicos examinam embriões humanos para verificar a ocorrência de distúrbios genéticos tais como, por exemplo, a doença de Huntington. Suponhamos que os médicos detectem o problema em alguns embriões, e que eles sejam bem-sucedidos na correção da sequência de genes associada ao problema. Os médicos podem agora ter razoável certeza de que, ao se tornarem adultos, esses embriões jamais desenvolverão a doença de Huntington. Mas vamos supor também que, durante o procedimento de edição genômica, uma mutação inesperada ocorra, e que isso ocasione mais tarde o nascimento de crianças com graves problemas cognitivos. A única maneira de reverter esse problema consistiria na utilização de um "novo procedimento", que permite elevar a capacidade cognitiva das crianças a um patamar considerado normal. A pergunta que podemos então nos colocar é a seguinte: existe uma obrigação moral de proporcionarmos a essas crianças o acesso ao "novo 
procedimento"? Parece-me que a maioria das pessoas concordaria que temos essa obrigação. A expectativa de viver uma vida melhor, uma vida que permitiria às crianças realizar uma diversidade de capacidades humanas, ficaria comprometida se fosse negado a elas o acesso ao "novo procedimento". Mas algumas pessoas poderiam também alegar que estamos autorizados a usar o "novo procedimento" neste cenário porque (e somente porque) o que está em questão aqui não é o "aprimoramento", mas o "tratamento" de uma deficiência cognitiva. Num artigo de 2003, Leon Kass, por exemplo, afirma o seguinte: “Terapia genética para fibrose cística ou Prozac para depressão psicótica é aceitável; inserção de genes para aprimorar [enhance] a inteligência ou esteroides para atletas olímpicos, não”. (Kass, 2003, p. 13).

A distinção entre o que está em questão no primeiro cenário hipotético e o tipo de prática condenada por Kass pode ser representada, respectivamente, através das figuras 1 e 2 .
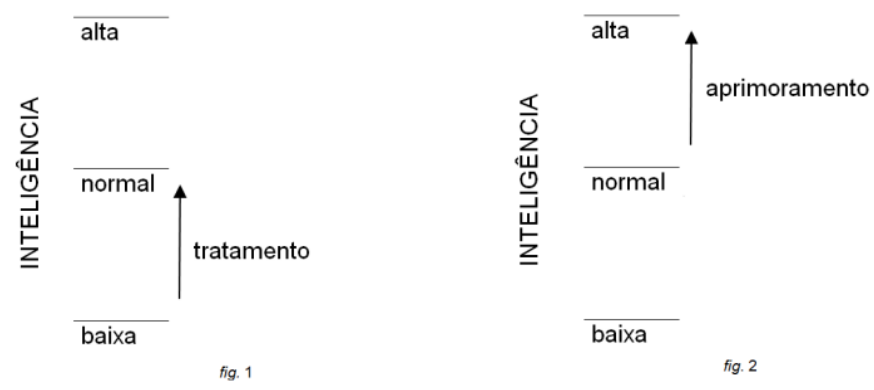

Imaginemos agora um segundo cenário. Neste cenário, a tentativa de se eliminar a doença de Huntington também é bem-sucedida, mas agora uma mutação inesperada leva ao nascimento de crianças com uma capacidade cognitiva extraordinariamente alta. Contudo, tal como ocorreu no cenário anterior, um "novo procedimento" permite que essa situação seja revertida. Isso garantiria que as crianças possam ter um nível de rendimento cognitivo igual ao de outras crianças normais. A questão que temos então de nos colocar é a seguinte: temos, também nesse caso, a obrigação moral de intervir na capacidade cognitiva dessas crianças? Parece-me que a maioria das pessoas concordaria que, nesse caso, não temos essa obrigação. As crianças que estão acima da média, no que diz respeito ao desempenho cognitivo, são algumas vezes chamadas de "superdotadas", como se elas tivessem sido agraciadas com uma espécie de "dote" natural. Às vezes, esse "dote" é também chamado de "dom." As crianças superdotadas são geralmente incentivadas a 
cultivar a própria inteligência. E isto pode ser feito, por exemplo, através de programas de educação especial.

Muitos países têm seus próprios programas para educação especial de crianças superdotadas, às vezes denominados em inglês de GATE-Programs (Gifted and Talented Education). A tomada de decisão nos programas GATE geralmente ocorre ao nível municipal ou estadual. Mas os governos, ao nível federal, têm a obrigação de garantir que todas as crianças superdotadas tenham igual acesso a programas de educação especial, independentemente de gênero, religião ou origem étnica (Grissom e Redding, 2016). ${ }^{5}$ De acordo com um documento emitido pelo governo brasileiro, precisam de educação especial não apenas as crianças que têm dificuldade de aprendizagem, mas também aquelas reconhecidas como "superdotadas." O documento, publicado pelo Ministério da Educação em 2001, afirma o seguinte:

\begin{abstract}
Além desse grupo [sc. o das crianças com déficit cognitivo], determinados segmentos da comunidade permanecem igualmente discriminados e à margem do sistema educacional. É o caso dos superdotados, portadores de altas habilidades, 'brilhantes' e talentosos que, devido a necessidades e motivações específicas - incluindo a não aceitação da rigidez curricular e de aspectos do cotidiano escolar - são tidos por muitos como trabalhosos e indisciplinados, deixando de receber os serviços especiais de que necessitam, como por exemplo o enriquecimento e aprofundamento curricular (Brasil, 2001a). ${ }^{6}$
\end{abstract}

$\mathrm{Na}$ discussão sobre políticas públicas para a educação de crianças superdotadas, pode surgir a questão sobre qual é realmente o objetivo dessas políticas: [1] garantir que as crianças superdotadas não se sintam desestimuladas em sala de aula, de modo que elas possam ter um desempenho cognitivo igual ao desempenho das outras crianças; ou [2] garantir que as crianças superdotadas realizem todo o potencial de que elas são capazes, atingindo portando um desempenho cognitivo superior ao rendimento das demais crianças. Parece-me que é a segunda meta que é visada pelas políticas públicas para a educação de crianças superdotadas. ${ }^{7}$

O rendimento escolar das crianças superdotadas, que são beneficiadas por programas de educação especial, é geralmente superior ao rendimento das crianças "normais." Mas essa forma de desigualdade não tem de ser percebida como um tipo de injustiça. A própria existência de programas para educação especial se baseia na suposição de que as crianças superdotadas devem ter a oportunidade de cultivar suas capacidades cognitivas especiais. Ninguém poderia razoavelmente propor uma política de educação que buscasse promover a igualdade de oportunidades nas escolas públicas 
através de medidas que neutralizassem os "dons" ou "dotes" naturais com os quais algumas crianças parecem ter sido agraciadas. Essa política de educação seria tão contrária à nossa percepção ordinária acerca do que consideramos melhor para as crianças quanto a tentativa de se neutralizar a mutação inesperada - a que me referi na apresentação do segundo cenário - através da aplicação de algum "novo procedimento" que nos permitisse reduzir o nível de inteligência das crianças a um patamar considerado normal. Essa forma bizarra de promover a igualdade de oportunidade entre as crianças pode ser representada esquematicamente através da figura 3.

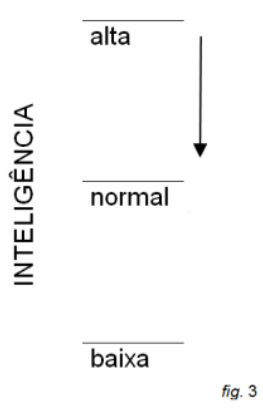

Mas se não faz sentido neutralizar os "dons naturais" com os quais algumas crianças são agraciadas, por que então seria moralmente errado - como sugere por exemplo Kass na passagem citada acima - usar algum "novo procedimento" para elevar a capacidade cognitiva de crianças normais ao nível de performance de que são capazes as crianças talentosas? Evidentemente, as expressões “dom natural” e "ser agraciado" estão sendo usadas aqui em um sentido figurado, pois não existe uma entidade que tenha a capacidade de "agraciar" as pessoas com tais e tais "dons" ou "dotes." É por essa razão que alguém poderia talvez preferir falar aqui em "talentos" ao invés de falar em "dons" ou "dotes" naturais. Mas a palavra "talento" também tem uma conotação metafísica. Ela significava originalmente um benefício financeiro que poderia ser dado a algumas pessoas. Essa utilização da palavra "talento" ocorre, por exemplo, no Novo Testamento, na "parábola dos talentos" (Mateus 25: 14-30). Mais tarde, a palavra "talento" passou a designar também uma espécie de "presente" dado por Deus a algumas pessoas. E é somente a partir do século XVIII que a "natureza", ao invés de Deus, passa a ser vista como a entidade que conferiria aos indivíduos tais e tais habilidades excepcionais (Lühe, 1998).

No debate sobre o aprimoramento cognitivo é possível percebermos o quanto a ideia de "talentos" ou "dons" ainda preserva resíduos da conotação religiosa e metafísica 
que essas palavras originalmente tinham. Uma das razões pelas quais, por exemplo, Francis Fukuyama se posiciona contra a busca pelo aprimoramento cognitivo é a seguinte: “O propósito original da medicina é, afinal, curar os doentes, e não transformar pessoas saudáveis em deuses" (Fukuyama, 2002, p. 209). Para Fukuyama, elevar o nível de inteligência das pessoas normais ao mesmo nível de performance cognitiva de indivíduos superdotados equivaleria a arrogar para si um poder que somente Deus poderia exercer.

Até mesmo documentos que evitam o uso de ideias teológicas acabam se comprometendo, de modo implícito, com a suposição de que algumas de nossas habilidades naturais devem ser compreendidas como uma espécie de "dádiva." Em 2015, por exemplo, o Comitê Internacional de Bioética da UNESCO publicou um relatório sobre o uso de novas tecnologias para edição genômica. O Comitê se mostra preocupado com relação à possibilidade de que, no futuro, a edição genômica possa vir a ser usada para fins de aprimoramento, e não apenas para fins de tratamento. O relatório emprega a palavra endowment para se referir às habilidades especiais que algumas pessoas têm. $\mathrm{O}$ problema, porém, é que a palavra endowment também envolve a ideia de um "presente" ou "dote." O documento afirma o seguinte:

\begin{abstract}
O objetivo do aprimoramento [enhancing] de indivíduos e da espécie humana por meio da engenharia de genes relacionados a características e propriedades específicas não deve ser confundido com os projetos bárbaros de eugenia que planejavam a simples eliminação de seres humanos considerados 'imperfeitos' a partir de bases ideológicas. No entanto, esse objetivo viola [impinges] o princípio do respeito pela dignidade humana de diversas formas. Ele enfraquece a ideia de que as diferenças entre seres humanos, independentemente da medida de seus dotes [endowment], são exatamente o que o reconhecimento da igualdade pressupõe e portanto protege (UNESCO (2015, p. 27, §111).
\end{abstract}

Segundo o Comitê Internacional de Bioética da UNESCO, a tentativa de modificarmos os "dotes" (endowments) naturais das pessoas por meio de novas tecnologias constitui uma violação do "princípio do respeito à dignidade humana." A referência ao "princípio do respeito à dignidade humana" nesse contexto constitui, a meu ver, uma tentativa de se reintroduzir, de modo sub-reptício, uma ideia teológica através de uma linguagem secular. Afinal, um "dote" pressupõe sempre a existência de um "doador", de uma entidade à qual deveríamos respeito e gratidão pelos "dotes" que recebemos. Mas esse “doador” simplesmente não existe. Ou se existe, é difícil darmos um sentido a essa ideia num debate em que premissas teológicas ou metafísicas não 
deveriam ser impostas a pessoas que não compartilham essas ideias. Os críticos do aprimoramento cognitivo, de modo implícito ou explícito, frequentemente se comprometem com essa concepção metafísica de "talentos" ou "dotes" naturais. Michael Sandel, por exemplo, afirma o seguinte: "Se a engenharia genética nos permitisse sobrepujar os resultados da loteria genética e substituir o acaso pela escolha, o caráter de dádiva [gift] das potências e das conquistas humanas desapareceria" (Sandel, 2013, p. 102).

Para os críticos do aprimoramento cognitivo o nível médio de inteligência humana tem um caráter normativo: nós não deveríamos nos afastar muito da "linha da normalidade", a menos que tenhamos sido excepcionalmente "agraciados" (endowed), pela natureza ou por Deus, com talentos ou dons especiais - isso que Sandel chama de “dádiva" (gift), ou aquilo que o documento da UNESCO chama de "dote" (endowment). Mas essa suposição é equivocada. Ela é equivocada, em primeiro lugar, porque é preciso aceitarmos, ainda que de modo implícito, ideias metafísicas ou religiosas para aceitarmos também, como pretendem Kass, Sandel e Fukuyama, a suposição de que a "linha da normalidade" tenha um caráter normativo. Essa suposição é também equivocada, em segundo lugar, porque a própria ideia de uma "linha de normalidade" é problemática. O nível médio de desempenho cognitivo das pessoas não é fixo. O QI da população mundial, como demonstram diversos estudos longitudinais, tem aumentado de forma constante ao longo do século $\mathrm{XX}$, muito embora isso não venha ocorrendo no mesmo ritmo em todas as partes do mundo. Esse fenômeno é conhecido como o "efeito Flynn”.

\section{Efeito Flynn e políticas públicas}

A explicação para o efeito Flynn tem sido objeto de muita discussão, mas o fenômeno em si mesmo é bem documentado (Flynn, 2013; 2012; 2007). Acredita-se que o incremento do QI das pessoas seja atribuível à interação de diferentes fatores, tais como, por exemplo, melhor nutrição, educação compulsória para todas as crianças, e o surgimento de trabalhos cada vez mais exigentes em termos cognitivos. Outros fatores são menos aparentes, mas igualmente importantes para o aumento do QI das pessoas em diversas partes do mundo. Sabe-se, por exemplo, que a deficiência de iodo está associada ao retardo mental. Alguns estudos sugerem que o QI médio das populações que sofrem de deficiência de iodo é de 10 a 15 pontos inferior ao QI médio em populações que não sofrem de um déficit de iodo. Um documento publicado pela UNICEF em 2007 adverte 
que a deficiência de iodo ainda é um "grande problema de saúde pública na Europa." Este problema está associado a "graus sutis de deficiência mental" que contribuem para um menor desempenho acadêmico (UNICEF / World Health Organization, 2007, p. vii). ${ }^{8} \mathrm{O}$ combate à deficiência de iodo é geralmente feito através de políticas públicas que envolvem a iodização do sal. Esse é um procedimento bastante barato.

A iodização do sal pode ser vista aqui como um procedimento análogo ao "novo procedimento", a que me referi anteriormente na discussão do primeiro cenário hipotético. Tanto num caso como no outro os tomadores de decisão concordam que temos a obrigação moral de usarmos todos os meios que estão ao nosso alcance na tentativa de impedir que uma criança tenha um rendimento cognitivo abaixo do rendimento considerado normal. ${ }^{9}$ Mas a questão que podemos nos colocar agora é a seguinte: uma vez que o problema relativo à deficiência cognitiva das crianças tenha sido resolvido seja através da iodiozação do sal ou através da aplicação de um hipotético "novo procedimento" -, por que então não poderíamos dar um passo além, se esse passo estiver a nosso alcance? Por que, com outras palavras, não poderíamos aumentar o QI das crianças a níveis ainda mais elevados do que aqueles considerados normais, se tivermos recursos para fazer isso de modo eficaz e seguro? A meu ver, não há nenhuma razão para rejeitarmos de antemão a promoção do aprimoramento cognitivo como uma questão de saúde pública. Afinal, como diversos estudos longitudinais sobre o efeito Flynn mostram, isso já vem sendo feito ao longo das últimas décadas. A implementação de políticas públicas como a iodização do sal, a educação compulsória para todas as crianças, e a criação de programas para a educação especial de crianças superdotadas, têm contribuído para um aumento genealizado do QI da população mundial. E conforme o QI da população mundial aumenta, a "linha da normalidade" se desoloca gradualmente para um patamar superior. A "linha da normalidade", portanto, diferentemente do que alguns críticos do aprimoramento cognitivo acreditam, não é fixa (Vilaça e Dias, 2015). Não existe realmente um nível "natural" de inteligência que devêssemos tomar como normativo. É a figura 4 que, a meu ver, melhor representa o problema que está em questão na discussão sobre o aprimoramento cognitivo de grandes populações. Num período de poucas décadas, que se estende de $t_{1}$ a $t_{4}$, o nível médio de inteligência das pessoas pode variar bastante. 


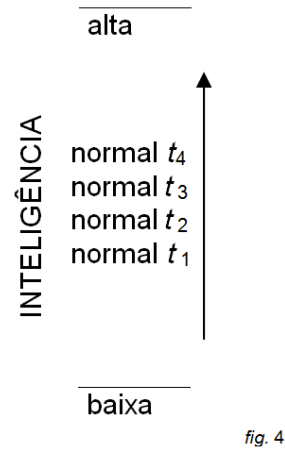

Evidentemente, podemos nos perguntar se o aumento de QI da poupulação mundial ao longo do século XX poderia ser realmente considerado como um tipo de “aprimoramento cognitivo." Cameron Clark e colegas, por exemplo, sustentam que o efeito Flynn não deve ser compreendido como uma forma de "aprimoramento cognitivo real de nossa espécie.” Num artigo de 2016, eles afirmam o seguinte:

\begin{abstract}
A tese central deste artigo é que embora seja conveniente concluir que aumentos na medição de pontos de QI, ao longo do século XX, representem uma espécie de aprimoramento cognitivo real ou direito de nossa espécie, estes aumentos devem ser vistos, mais apropriadamente, como incrementos reais no desempenho em testes de QI, devido a ambientes cognitivos aprimorados impostos à nossa espécie pelos ambientes sociais e culturais do século XX, e provavelmente anteriormente; ou seja: o efeito Flynn não representa aumentos genuínos em inteligência geral, mas na verdade aumento do desempenho em testes de QI devido a uma crescente adaptação para os tipos de raciocínios modernos que a vida moderna exige, e que testes de QI medem (Clark et al., 2016, p. 41).
\end{abstract}

A vida moderna nos apresenta uma série de tarefas cognitivamente exigentes. Um número crescente de pessoas tem de processar uma enxurrada de informações, e lidar com uma variedade de símbolos, tabelas, gráficos, e estatísticas todos os dias. Além disso, nós nos acostumamos a expressar nossas próprias ideias por meio de abstrações e raciocínios hipotéticos. A linguagem da ciência permeia nossa linguagem cotidiana de uma forma que seria familiar apenas a um número limitado de pessoas até o início do século XX. Clark e seus colegas, portanto, têm razão ao sugerirem que os nossos antepassados não eram de modo geral menos "inteligentes" do que somos agora, mesmo admitindo que nossos antepassados teriam mostrado claros sinais de retardo mental, se tivessem sido submetidos aos testes de QI que são aplicados hoje em dia. Essa assimetria entre os níveis de desempenho nos testes de QI do passado e a pontuação média obtida hoje em dia é às vezes denominada de "paradoxo do retardo mental." ${ }^{10}$ Mas o paradoxo é apenas aparente. 
Nossos bisavôs e bisavós simplesmente não tiveram de enfrentar as mesmas tarefas cognitivas e os mesmos quebra-cabeças intelectuais que enfrentamos diariamente ao buscarmos, por exemplo, informações na internet, ou quando nos deslocamos em uma grande cidade, seguindo diagramas e símbolos que aprendemos a interpretar sem dificuldades. Testes de QI servem para avaliar nossa capacidade para lidar com os desafios cognitivos típicos da vida moderna, e não a nossa capacidade de lidar com as tarefas do mundo pré-industrial.

No entanto, diferentemente do que Clark e colegas sugerem, o que está em jogo no debate sobre o "aprimoramento cognitivo" não é tanto a questão sobre se podemos ou não obter "aumentos genuínos na inteligência geral." É claro a aquisição de "aumentos genuínos na inteligência geral" deveria ser caracterizada como um caso de aprimoramento cognitivo. Mas o debate contemporâneo sobre aprimoramento cognitivo não se concentra sobre esse tipo de aquisição. $O$ debate sobre aprimoramento cognitivo incide basicamente sobre o uso de "novos procedimentos" para aumentar nosso rendimento em uma diversidade de tarefas cognitivamente relevantes. Esses "novos procedimentos" incluem, por exemplo, o uso de drogas como modafinil e metilfenidato; dispositivos para tDCS (estimulação transcraniana de corrente direta); e, possivelmente no futuro, o recurso à edição genômica e seleção de embriões. Esses "novos procedimentos" têm o potencial para ajudar às pessoas a lidar com os desafios da vida moderna, e a explorar as oportunidades que a vida moderna oferece. ${ }^{11}$

\section{Conclusão}

Se novas drogas como modafinil ou metilfenidato, ou técinas para edição genômica, ou ainda próteses cerebrais e dispositivos para tDCS se tornarem realmente eficazes e seguros para fins terapêuticos no futuro, não há razão alguma para supormos que eles não deveriam jamais ser usados para fins de aprimoramento cognitivo também. Esses "novos procedimentos" podem vir a nos ajudar a viver em ambientes que, provavelmente, serão ainda mais exigentes em termos cognitivos do que os ambientes em que vivemos atualmente. $\mathrm{O}$ aprimoramento cognitivo, portanto, pode se tornar necessário no futuro da mesma forma que a produção de antibióticos e programas de vacinação em massa se tornaram indispensáveis na tentativa de tornar nosso sistema imunológico capaz de combater agentes patogénicos a que não havíamos sido expostos antes, ou que não estávamos devidamente preparados para enfrentar no passado. 
No futuro, os tomadores de decisão podem, portanto, vir a considerar a busca pelo o aprimoramento cognitivo da população como uma obrigação relativamente aos cidadãos. A busca pelo aprimoramento cogntivo da população poderia assim ser vista como uma questão de saúde pública por força das mesmas razões que medidas como a iodização do sal, a vacinação em massa, e a criação de programas para educação especial de crianças superdotadas foram implementadas em nosso passado recente ${ }^{12}$. 


\section{Notas}

1 Pesquisador Bolsista de Produtividade do CNPq. Professor de Filosofia do Direito da Universidade Federal do Rio de Janeiro (UFRJ). Professor de Ética da Universidade do Estado do Rio de Janeiro (UERJ), Rio de Janeiro, R. J., Brasil. e-mail: marcelo.araujo@pq.cnpq.br

2 Empregarei a expressão "aprimoramento cognitivo" neste artigo como tradução da expressão correlata em inglês cognitive enhancement.

${ }^{3}$ Eu discuti esse ponto em outras publicações: (Araujo, 2014; Araujo, 2016a; Araujo, 2016b).

${ }^{4}$ Essa objeção pode ser atribuída, por exemplo, a Sandel (2007); Kass (2003); Fukuyama (2002); Habermas (2002).

${ }^{5}$ Ver também BBC Brasil (2016).

${ }^{6}$ Ver também BRASIL (2001b, artigo 5, parágrafo III), esse documento define uma criança superdotada como aquela que possui "altas habilidades/superdotação, grande facilidade de aprendizagem que os leve a dominar rapidamente conceitos, procedimentos e atitudes."

${ }^{7}$ BRASIL (2006, p. 11): "Várias são as razões para justificar a necessidade de uma atenção diferenciada ao superdotado. Uma delas é por ser o potencial superior um dos recursos naturais mais preciosos, responsável pelas contribuições mais significativas ao desenvolvimento de uma civilização.”

${ }^{8}$ Ver também Aburto et al. (2014, p. 10); J. Feyrer et al. (2013); Steen (2009, p. 83).

${ }^{9}$ Ver por exemplo Schwarz (2012), que relata o caso do pediatra que prescrevia o medicamento Adderall, indicado para o tratamento de transtorno do déficit de atenção com hiperatividade, para crianças de baixa renda, que não tinham sintomas desse transtorno. A prescrição era feita para que as crianças pudessem ter um desempenho escolar tão bom quanto o de outras crianças da mesma faixa etária. A medicação foi realizada com o consentimento dos pais e, de fato, parece ter contribuído para um aumento do rendimento escolar das crianças medicadas. Nesse caso, porém, o pediatra tomou uma decisão particular, que não foi orientada ou acompanhada por algum tipo de política pública oficial, e que não levava em consideração, por exemplo, os riscos que esse tipo de prática pode representar para a saúde das crianças.

${ }^{10}$ Flynn (2007, p. 9-10): "The mental retardation (MR) paradox: If we project IQ gains back to 1900, the average IQ scored against current norms was somewhere between 50 and 70. If IQ gains are in any sense real, we are driven to the absurd conclusion that a majority of our ancestors were mentally retarded."

${ }^{11}$ Para uma discussão recente sobre o debate em torno do aprimoramento cognitivo, ver por exemplo a coletânea de artigos organizada por Jotterand e Dubljevic (2016).

${ }^{12}$ Uma primeira versão deste artigo foi apresentada na PUC-Porto Alegre em dezembro de 2016. O autor gostaria de agradecer a Nythamar Oliveira pelo convite para a apresentação e discussão deste trabalho em seu seminário de pesquisa. Pelos comentários críticos a uma versão preliminar deste artigo, o autor gostaria de agradecer também a Daniel Vasconcelos, Maria Clara Dias, e Cinara Nahra. 


\section{Referências}

Araujo, Marcelo de. 2014. "Moral enhancement and political realism". Journal of Evolution and Technology, vol. 24, n. 2, p. 29-43.

Araujo, Marcelo de. 2016a. "Ética nos esportes: Revisitando a questão do doping à luz do debate sobre aprimoramento humano". Prometeus, vol. 9, n. 20, p. 17-39.

Araujo, Marcelo de. 2016b. "Entre o tratamento e o aprimoramento humano?" (entrevista). In: Revista do Instituto Humanitas Unisinos. São Leopoldo, vol. 487, ano 16, p. $37-42$

Aburto, Nancy; Abudou, Minawaer; Candeias, Vanessa; Wu, Tiaxiang. 2014. Effect and safety of salt iodization to prevent iodine deficiency disorders: A systematic review with meta-analyses. Geneva: World Health Organization.

BBC Brasil. 2016. "Matemática, música e bullying: como é a vida de crianças superdotadas no Brasil." 26 de novembro de 2016. Disponível em: http://www.bbc.com/portuguese/geral-38082450 (acessado em 27 jan 2017).

Brasil - Ministério da Educação. 2006. Educação infantil altas habilidades / superdotação. Saberes e práticas da inclusão. Brasília: Ministério da Educação Secretaria de Educação Especial.

Brasil - Ministério da Educação. 2001a. "Diretrizes nacionais para a educação especial na educação básica". Brasília: Ministério da Educação Secretaria de Educação Especial, Resolução CNE/CEB N 2, de 11 de setembro de 2001.

Brasil - Ministério da Educação. 2001b. "Diretrizes nacionais para a educação especial na educação básica”. Documento emitido por Conselho Nacional de Educação - Câmara de Educação Básica. Processo n. 23001-000184/2001-92, aprovado em 3 de julho de 2001.

Clark, Cameron M.; Lawlor-Savage, Linette; Goghari, Vina M. 2016. "The Flynn effect: A quantitative commentary on modernity and human intelligence". Measurement, vol. 14 , n. 2, p. 39-53.

Feyrer, James; Politi, Dimitra; Weil, David N. 2013. "The cognitive effects of micronutrient deficiency: Evidence from salt iodization in the United States". National Bureau of Economic Research. (doi: 10.3386/w19233). Disponível em: http://www.nber.org/papers/w19233 (acessado em 27 jan 2017).

Flynn, James. 2007. What is intelligence? Beyond the Flynn effect. Cambridge: Cambridge University Press.

Flynn, James. 2012. Are we getting smarter? Rising IQ in the twenty-first century. Cambridge: Cambridge University Press. 
Flynn, James. 2013. Intelligence and human progress. The story of what was hidden in our genes. Amsterdam: Elsevier.

Fukuyama, Francis. 2002. Our posthuman future: Consequences of the biotechnology revolution. New York: Farrar, Straus and Giroux.

Grissom, Jason A.; Redding, Christopher. 2016. "Discretion and disproportionality: Explaining the underrepresentation of high-achieving students of color in gifted programs". AERA (American Educational Research Association) Open, vol. 2, n, 1 p. 125 .

Habermas, Jürgen. 2002. Die Zukunft der menschlichen Natur: Auf dem Weg zu einer liberalen Eugenik?. Frankfurt: Suhrkamp.

Jotterand, Fabrice; Dubljević, Veljko (eds.). 2016. Cognitive enhancement: Ethical and policy implications in international perspectives. Oxford: OUP.

Kass, Leon R. 2003. "Ageless bodies, happy souls: Biotechnology and the pursuit of perfection”. The New Atlantis. [Primavera], p. 9-28.

Lühe, A. 1998. “Talent”. Historisches Wörterbuch der Philosophie. Basel: Schwabe, vol. 10 , p. 886-985.

Sandel, Michael, 2013. Contra a perfeição. Ética na era da engenharia genética. Trad. Ana Carolina Mesquita. Rio de Janeiro: Civilização Brasileira.

Sandel, Michael. 2007. The case against perfection: Ethics in the age of genetic engineering. Cambridge (Mass): Harvard University Press.

Schwarz, Alan . 2012. "Attention disorder or not, pills to help in school". New York Times, 9 de outubro de 2012 . Disponível em: http://www.nytimes.com/2012/10/09/health/attention-disorder-or-not-childrenprescribed-pills-to-help-in-school.html (acessado em 27 jan 2017).

Steen, R. Grant. 2009. Human intelligence and medical illness: Assessing the Flynn effect. New York: Springer.

UNESCO. 2015. "Report of the IBC on updating its reflection on the human genome and human rights". Paris 2 de outubro de 2015. Disponível em: http://unesdoc.unesco.org/images/0023/002332/233258e.pdf (acessado em 27 jan 2017).

UNICEF / World Health Organization. 2007. Iodine deficiency in Europe: A continuing public health problem. New York: UNICEF.

Vilaça, Murilo Mariano; Dias, Maria Clara. 2015. "Tratar, sim; melhorar, não? Análise crítica da fronteira terapia/melhoramento". Revista de Bioética, vol. 23, n. 2, p. 267-76. 